\title{
Evidence for Two Virulence Determinants in the Fireblight Pathogen Erwinia amylovora
}

\author{
By ROBERT A. BENNETT† \\ East Malling Research Station, Maidstone, Kent ME19 6BJ
}

(Received 21 May 1979)

\begin{abstract}
Seven avirulent strains of Erwinia amylovora were mixed in various combinations and tested for virulence. Only one combination, where the capsulated avirulent strain P66 was combined with the non-capsulated avirulent strain $4 \mathrm{~S} 2$, induced fireblight symptoms in immature pear fruits and apple shoots. Growth studies in vivo strongly suggested that these strains were acting synergistically and that the non-capsulated strain possessed another, as yet unknown, virulence factor.
\end{abstract}

\section{INTRODUCTION}

Previous work indicated that virulence in the fireblight pathogen Erwinia amylovora is associated with the presence of a capsule and/or the production of an extracellular polysaccharide (Bennett \& Billing, $1978 a, b$; Bennett, 1978 $a, b$; Bennett \& Billing, 1980). However, the existence of a capsulated strain (P66) which produces polysaccharide but is avirulent suggests that these cannot be the only virulence determinants.

The purpose of the experiments described below was to see whether the missing determinant could be supplied from avirulent non-capsulated strains by co-inoculating them with P66 into susceptible plant tissue. Some of this work has been outlined briefly elsewhere (Bennett \& Billing, 1978b; Bennett, 1978a,b).

\section{METHODS}

Cultures. Seven avirulent strains were selected from a collection at East Malling Research Station (EMRS) and are listed in Table 1 . The highly virulent reference strain $\mathrm{T}$ was included as a control.

Plant material. Immature 'Conference' pear fruits and 1 year-old M26 apple rootstock layers were used. The pear fruits were surface sterilized after removal of the stalk and calyx ends by immersion for $30 \mathrm{~min}$ in Domestos (Lever Bros.) diluted 1/400 to give a final concentration of about 250 p.p.m. available chlorine. The fruits were subsequently washed in sterile distilled water containing a few crystals of sodium thiosulphate and once in sterile distilled water alone. They were then placed on a pad of sterile wet filter paper in an open Petri dish and put inside an enclosed container to maintain a moist atmosphere.

The apple rootstock layers were potted individually in standard EMRS potting compost and held dormant at $5{ }^{\circ} \mathrm{C}$ until required. Succulent shoots were forced in a warm $\left(15\right.$ to $\left.25^{\circ} \mathrm{C}\right)$ greenhouse and thinned to one shoot per plant when they were 5 to $10 \mathrm{~cm}$ long. When the actively growing shoots were about $25 \mathrm{~cm}$ long, plants were transferred either to an experimental greenhouse or a growth cabinet. The temperature in the experimental greenhouse was maintained as far as possible between 15 and $25^{\circ} \mathrm{C}$. In the growth cabinet (Fisons, model $600 \mathrm{G} 3 / \mathrm{TTL}$ ) a $16 \mathrm{~h}$ light-8 $\mathrm{h}$ dark cycle was maintained with respective day and night temperatures of $24{ }^{\circ} \mathrm{C}$ and $15^{\circ} \mathrm{C}$. As experiments were normally completed within 2 weeks, nutrient solutions were not supplied but pots were kept well watered on a capillary bed. Plants were allowed to acclimatize to the greenhouse or growth cabinet conditions for $5 \mathrm{~d}$ before being inoculated.

Inoculations. Inoculum was prepared in yeast peptone broth (YPB) which contained $\left(\mathrm{g} \mathrm{l}^{-1}\right)$ : Oxoid yeast extract, 3; Oxoid peptone, 5. The $\mathrm{pH}$ of the medium was adjusted to 6.9 to $7 \cdot 1$ before autoclaving at $121{ }^{\circ} \mathrm{C}$ for $15 \mathrm{~min}$. Cultures were grown overnight at $25^{\circ} \mathrm{C}$ in a rotary shaker incubator (L.H. Engineering, Stoke

$\dagger$ Present address: Agricultural Research Council, Letcombe Laboratory, Wantage OX12 9JT. 
Table 1. Origin of selected strains and some of their characteristics

\begin{tabular}{|c|c|c|c|c|c|c|}
\hline Strain & Isolate & Host & $\begin{array}{l}\text { Selection } \\
\text { method }\end{array}$ & $\begin{array}{c}\text { Capsula- } \\
\text { tion }\end{array}$ & $\begin{array}{l}\text { Ooze-like } \\
\text { polysaccharide } \\
\text { production } \\
\text { in vitro }\end{array}$ & Virulence \\
\hline $\mathrm{T}$ & $\mathbf{T}$ & Pear & Wild-type & + & + & + \\
\hline P66 & P66 & Pear & Colony & + & + & - \\
\hline $3 \mathrm{~A} 2 \mathrm{~B}$ & $3 \mathrm{~A}$ & Pear & Colony & - & - & - \\
\hline P70 & P70 & Pear & Colony & - & - & - \\
\hline $4 \mathrm{SI}$ & & & Phage- & - & - & - \\
\hline $4 \mathrm{~S} 2$ & $\mathrm{~T}$ & Pear & resistant & - & - & - \\
\hline 4L1 & & & mutants & - & - & - \\
\hline E8 & E8 & Apple & Colony & - & - & - \\
\hline
\end{tabular}

Strain T is a highly virulent wild-type strain used by Dr E. Billing since 1970. All isolates were from a collection at East Malling Research Station, except E8 which was provided by Professor R. N. Goodman, Columbia University, Mo., U.S.A.

Poges, Bucks.) and adjusted to give a reading of 15 on a Corning EEL nephelometer (this is equivalent to about $1 \times 10^{8}$ cells $\mathrm{ml}^{-1}$ ). Each strain was then mixed in equal proportions with each of the other avirulent strains just before inoculation into immature pear fruits or apple shoots.

The pear fruits were stab-inoculated through the side using a straight wire which had been dipped in the prepared inoculum and then incubated in a constant temperature room at $18^{\circ} \mathrm{C}$. At daily intervals, selected specimens were sliced open along the line of inoculation and examined for symptom development.

The apple shoots were inoculated just below the tip by removing leaf -1 (the leaf above the last unfolded leaf) and placing a $10 \mu \mathrm{l}$ drop of inoculum, with a 'Finnpipette', on the resulting scar. They were then examined daily for the appearance of fireblight symptoms.

In preliminary experiments the only combination of avirulent strains which produced any symptoms in either pear fruits or apple shoots was that of the capsulated strain P66 and the non-capsulated strain 4S2 (see Results). To determine whether the effects produced by this combination were due to the selection of a new virulent mutant or to a synergistic reaction, the following experiments were carried out.

Pear fruits were prepared, inoculated and incubated as previously described. After 3 to $4 \mathrm{~d}$ incubation, infected pears were sliced open along the line of inoculation and small $(2 \times 2 \times 2 \mathrm{~mm})$ pieces of tissue were removed from the leading edge of the spreading lesion. The tissue was ground in sterile distilled water, serial 10-fold dilutions were prepared and surface colony counts were made on yeast peptone agar (YPA) and YPA supplemented with $5 \%(\mathrm{w} / \mathrm{v})$ sucrose (YPSA). On these media, P66 and 4S2 produce distinct colony forms and so the plates could be examined for the appearance of new colony types. As none were observed, a series of P66- and 4S2-like colonies were selected, restreaked to check for purity and then re-inoculated into fresh pears separately and in combination. In addition, attempts were made to increase the population of virulent mutants or recombinants by serial host passage. Fresh pears were inoculated directly with the extracts from previously infected fruits. This procedure was repeated on five successive occasions.

Growth rates of strains $\mathrm{P} 66$ and $4 \mathrm{~S} 2$ in vivo and in vitro. Apple shoots were grown and maintained as previously described and transferred to the growth cabinet. They were subsequently inoculated with strains P66 and 4S2, separately and in combination, at a final dose of $1 \times 10^{6}$ viable cells per shoot. Strain T was included in these experiments at a similar dose for comparison. Actual doses were determined by making surface colony counts just prior to inoculation. Single shoots inoculated with the mixture or strain $T$ were sampled at 0800, 1200 and 1600 each day and shoots inoculated with either P66 or 4S2 alone were sampled at 0800 each day. The top $3 \mathrm{~cm}$ of shoot was ground in $1 \mathrm{ml}$ of sterile distilled water containing a little sharp sand. Serial 10-fold dilutions were prepared and surface colony counts were made on YPA and YPSA plates. Samples were also taken at $1 \mathrm{~cm}$ intervals down the shoot, ground as above and $10 \mu \mathrm{l}$ drops of the extracts were spotted on to YPA plates to determine how far the organism had migrated.

Growth rates in vitro of strains P66, 4S2 (separately and in combination) and T were determined at $24{ }^{\circ} \mathrm{C}$ in $50 \mathrm{ml}$ YPB in $250 \mathrm{ml}$ Erlenmeyer flasks on a rotary shaker incubator (L.H. Engineering). 

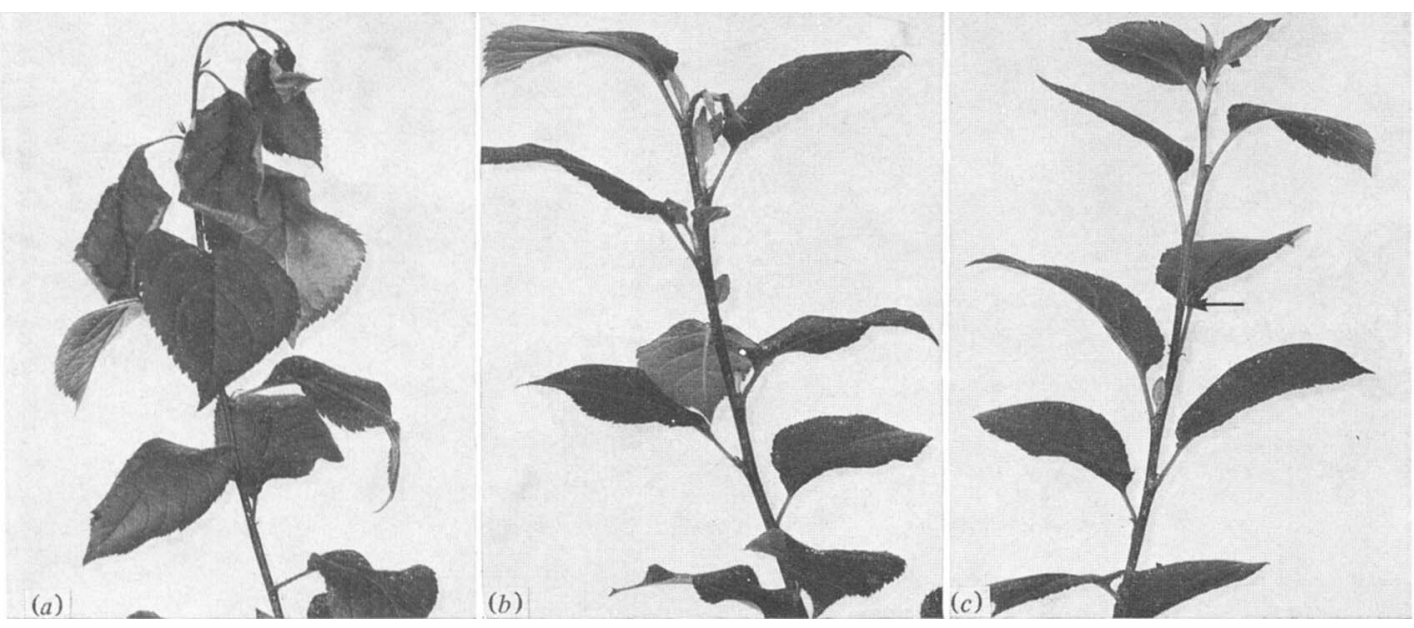

Fig. 1. Lesions produced in apple shoots $10 \mathrm{~d}$ after inoculation with: (a) virulent strain T; $(b)$ avirulent strains P66 and 4S2 in combination (note dead tip of shoot and new side shoots emerging from the axils of lower leaves); (c) either strain P66 or 4S2 alone (arrow shows the position of leaf scar -1 at the time of inoculation).

\section{RESULTS}

\section{Inoculation of pear fruits and apple shoots}

Of all the combinations tested, only the mixture containing the capsulated avirulent strain P66 and the non-capsulated avirulent strain 4S2 showed any symptoms in either pear fruits or apple shoots.

After $48 \mathrm{~h}$ incubation, pear fruits inoculated with the virulent reference strain $\mathrm{T}$ showed no external symptoms, but when the pears were cut open a distinct water-soaked lesion was seen spreading away from the line of inoculation. After $72 \mathrm{~h}$ incubation, ooze was invariably seen exuding from the point of inoculation and the skin of the pear around this point had become necrotic. Internally, the water-soaked lesion increased in size with continued incubation until the whole pear was affected. Similar symptoms were observed in pears inoculated with the mixture of P66 and 4S2 but the rate of development was slower than with strain T. The size of the lesion increased more slowly and ooze was not observed until $6 \mathrm{~d}$ after inoculation.

Apple shoots inoculated with strain $\mathrm{T}$ first showed symptoms (water-soaking, ooze and wilt) $48 \mathrm{~h}$ after inoculation. On continued incubation the disease could be seen progressing down the shoot and after 8 to $10 \mathrm{~d}$ the whole shoot was dead. In contrast, shoots inoculated with the mixture showed slight wilting of the tip but no ooze production after $48 \mathrm{~h}$. On continued incubation, the tip of the shoot became completely necrotic but the infection did not spread more than $5 \mathrm{~cm}$ from the point of inoculation and no ooze was produced. New side shoots emerged from the axils of the lower leaves (Fig. 1).

\section{Stability of isolates during host passage}

On re-isolation from pears inoculated with the mixture of P66 and 4S2, approximately equal numbers of these two colony types were observed. No new colony types were seen on either medium, suggesting that virulent mutants or recombinants had not emerged. As a check, 10 colonies of each type were selected at random from a series of re-isolation plates and inoculated into fresh pears. When bacteria from either colony type alone were used no symptoms developed, but when bacteria from any P66-like colony were co-inoculated with bacteria from any 4 S2-like colony symptoms were always produced.

When fresh pears were inoculated with the extracts from pears infected with the mixture 


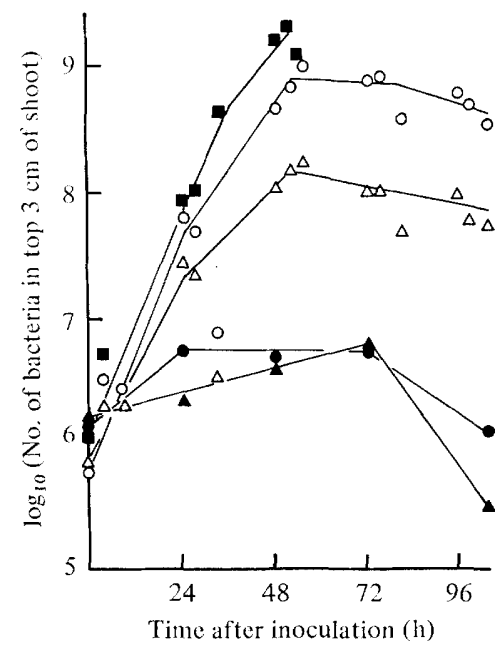

Fig. 2

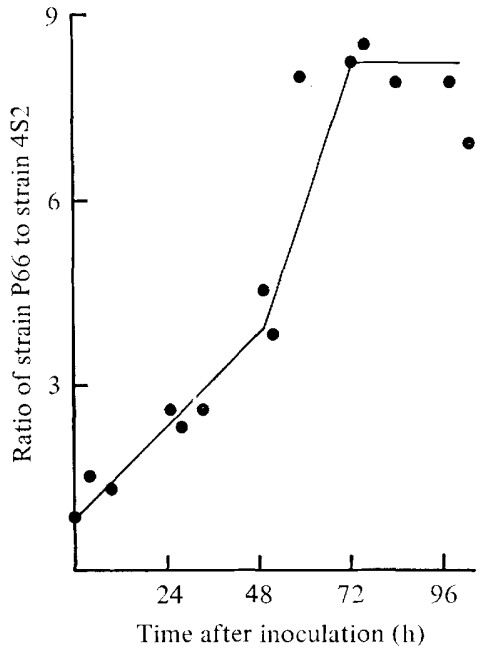

Fig. 3

Fig. 2. Growth rates of Erwinia amylovora strains P66, 4S2 (separately and in combination) and $\mathrm{T}$ in apple shoots: $O$, P66 alone; $\Delta, 4 \mathrm{~S} 2$ alone; $\bigcirc, \mathrm{P} 66$ co-inoculated with $4 \mathrm{~S} 2 ; \triangle, 4 \mathrm{~S} 2$ co-inoculated with P66; $\square, \mathrm{T}$.

Fig. 3. Increase in the ratio of Erwinia amylovora strain P66 to strain 4S2 after co-inoculation into apple shoots.

Table 2. Doubling times of Erwinia amylovora strains P66, 4S2 (separately and in combination) and $\mathrm{T}$ in shaken yeast peptone broth at $24^{\circ} \mathrm{C}$

\begin{tabular}{lc}
\multicolumn{1}{c}{ Strain } & $\begin{array}{c}\text { Doubling time } \\
(\mathrm{min})\end{array}$ \\
T (alone) & 71 \\
P66 (alone) & 75 \\
4S2 (alone) & 72 \\
P66 (in combination with 4S2) & 79 \\
4S2 (in combination with P66) & 74
\end{tabular}

of P66 and 4S2, symptoms were always produced, and on re-isolation a mixture of the two colony types (but no others) was found. On the five successive occasions that this procedure was repeated the same results were obtained.

\section{Growth of bacteria in vivo and in vitro}

Growth rates measured in vivo are shown in Fig. 2. Shoots inoculated with strain $T$ were only sampled up to $48 \mathrm{~h}$ after inoculation as by this time they were all showing typical early symptoms and the infection was spreading rapidly down the stem. The mean doubling time during this period was between 3.5 and $4 \mathrm{~h}$ and the number of viable bacteria in the top $3 \mathrm{~cm}$ of shoot at the time of first symptom expression was about $1 \times 10^{9}$. Large numbers of bacteria (about $1 \times 10^{7}$ ) were also isolated up to $10 \mathrm{~cm}$ away from the point of inoculation.

During the first $48 \mathrm{~h}$, the mean doubling time for P66 when in combination with $4 \mathrm{~S} 2$ was similar to that of strain $\mathrm{T}$ but the growth rate of $4 \mathrm{~S} 2$ appeared to be slower. In contrast to the virulent strain, the mixture did not progress down the stem more than $5 \mathrm{~cm}$. After $48 \mathrm{~h}$, there was a levelling off and possibly a slight decrease in the population of P66 and 4S2. There was also a marked increase with time in the ratio of P66 to 4S2 (Fig. 3). The initial inoculum contained a ratio of P66 to $4 \mathrm{~S} 2$ of about $0 \cdot 8: 1$, but 3 to $4 \mathrm{~d}$ after inoculation the 
ratio had increased to $8: 1$ in the top $3 \mathrm{~cm}$ of shoot and in the lower samples (4 to $5 \mathrm{~cm}$ ) only P66 was recovered.

Shoots inoculated with either strain separately showed no observable symptoms $10 \mathrm{~d}$ after inoculation. However, both strains persisted at the site of inoculation and showed a slight increase in numbers during the first $3 \mathrm{~d}$ (Fig. 2). After this time, both began to decline and after $10 \mathrm{~d}$ neither was recovered.

The doubling times (in shaken YPB at $24{ }^{\circ} \mathrm{C}$ ) of strains T, P66 and 4S2 separately and $\mathrm{P} 66$ and 4S2 in combination are shown in Table 2. The doubling time for all three strains was between 70 and $80 \mathrm{~min}$. When P66 and 4S2 were grown together, there was no obvious effect on the growth of either.

\section{DISCUSSION}

The fact that symptoms were only produced when P66 and 4S2 were inoculated together suggests that either these strains were acting synergistically or that virulent mutants or recombinants were being produced. Subsequent evidence showed that the latter was not the case. No new colony forms were observed on any of the re-isolation plates and when bacteria from a random selection of P66-like and 4S2-like colonies were re-inoculated separately into pear fruits no symptoms were produced. But when bacteria from any P66like colony were co-inoculated with those from any 4 S2-like colony, symptoms always developed.

Symptom production in pear fruits inoculated with the mixture was always slower than in those inoculated with the highly virulent strain $\mathrm{T}$, and in apple shoots the mixture only produced a limited lesion. This showed that the mixture was not fully competent. One possible explanation for this might be that both strains lack one or more other virulence factors. Alternatively, although the strains may possess complementary virulence factors, the growth of either may be dependent on both strains being in close enough association within the host tissues to co-operate. If they become separated or if the growth or death rate of one is faster than that of the other the mixture ratio will be affected and this will lead to a slowing down of disease development.

The growth studies in vivo showed that the population of $4 \mathrm{~S} 2$ increased more slowly than that of P66 which resulted in the ratio of P66 to 4S2 being increased to about 8:1 within $72 \mathrm{~h}$ after inoculation. Furthermore, when isolations were made 4 to $5 \mathrm{~cm}$ from the point of inoculation only strain P66 was recovered showing that this strain had some advantage over 4S2. These results also offer further support to the idea that these strains are acting synergistically, since when one strain became dominant the infection stopped. They do not, however, explain the greater decrease in numbers of $4 \mathrm{~S} 2$. Two possibilities are that the growth rate of $4 \mathrm{~S} 2$ was slower than that of $\mathrm{P} 66$ or that $4 \mathrm{~S} 2$ was less able to survive in the host tissues and therefore had a higher death rate. More precise information here might aid in the elucidation of the rôle of the postulated virulence factors, capsulation and polysaccharide production. For example, does the fact that $4 \mathrm{~S} 2$ is non-capsulated make it more sensitive to toxic substances produced by the host? Do the capsules and polysaccharide prevent the bacteria from being agglutinated by host plant lectins as appears to be the case with Pseudomonas solanacearum (Sequeira \& Graham, 1977), or are they in fact necessary for binding the bacteria to a specific site within the host as suggested for some Rhizobium spp. (Dazzo \& Brill, 1977)?

The results of the preliminary growth rate experiments in vitro showed that in YPB at $24{ }^{\circ} \mathrm{C}$, P66 and 4S2 had similar doubling times both separately and in combination. Further studies, using different temperature regimes and alternative media, might show differences in the growth capabilities of these two strains which would help to explain their behaviour when co-inoculated in vivo.

The evidence presented elsewhere (Bennett \& Billing, 1978 $a, b$; Bennett, 1978 $a, b$; Bennett \& Billing, 1980) strongly suggests that capsulation and/or polysaccharide produc- 
tion are involved in virulence but are not the only factors. The results of this present study support this view and suggest that strain 4S2 contains another, as yet unknown, virulence factor. Further work using these strains could provide information on the processes involved during the early stages of infection.

This work was supported by an Agricultural Research Council Grant.

\section{REFERENCES}

BenNetT, R. A. (1978a). Characteristics of the fireblight pathogen in relation to virulence. Ph.D. thesis, University of London.

BennetT, R. A. (1978b). Characteristics of Erwinia amylovora in relation to virulence. Proceedings of the IVth International Conference on Plant Pathogenic Bacteria, vol. II, pp. 479-481.

Bennett, R. A. \& Billing, E. (1978 a). Capsulation and virulence in Erwinia amylovora. Annals of Applied Biology 89, 41-45.

BennetT, R. A. \& Billing, E. (1978b). Investigations on virulence determinants of Erwinia amylovora. Proceedings of the IIIrd International Congress of Plant Pathology, p. 69 (abstract).
Bennett, R. A. \& Billing, E. (1980). Origin of the polysaccharide component of ooze from plants infected with Erwinia amylovora. Journal of General Microbiology 116, 341-349.

Dazzo, F. B. \& Brill, W. J. (1977). Receptor sites on clover and alfalfa roots for Rhizobium. Applied and Environmental Microbiology 33, 132136.

Sequeira, L. \& Graham, T. L. (1977). Agglutination of avirulent strains of Pseudomonas solanacearum by potato lectin. Physiological Plant Pathology 11, 43-54. 